\title{
An Investigation into Empirical Ice Density Formulations for Dry Ice Growth on Cylinders
}

\author{
Pavlo Sokolov ${ }^{1, \dagger}$, Muhammad S.Virk ${ }^{1}$ \\ ${ }^{1}$ Institute of Industrial Technology, University of Troms $\phi$ - The Arctic University of Norway, Post Box 385, \\ 8505, Narvik
}

†Corresponding Author Email: pavlo.sokolov@uit.no

\begin{abstract}
This paper describes an investigation into the empirical accreted icing density formulations, namely the numerical fits by (Makkonen and Stallabrass, 1984) and (Jones, 1990). Typically, the icing severity is estimated 10 by the masses of the accreted ice, however, for this study the focus is primarily on the accreted ice densities and thicknesses for the main purpose of estimating the ice loads, in particular for the cases when the ice mass measurements are not readily available and other indirect measurements such as observed ice thicknesses can to be used as an estimate. The results were obtained for both the analytical and numerical modeling in comparison with the icing tunnel experiments. Seven different diameters of cylinders ranging from 20 to 298 $\mathrm{mm}$ are used. Analysis show that Makkonen and Stallabras (M\&S) fit tends to have good agreement with the smaller cylinders, while it tends to underestimate the icing thicknesses for the larger cylinder diameters. On the other hand, the Jones ice density formulation shows consistently better results for almost all tested cases and especially for the larger cylinder diameters. The results with the MVD approximation show good agreement mainly for smaller diameter cylinders whereas the agreement for the larger cylinders is not good primarily due to low values of droplet inertia parameter $K$, which puts the results using the MVD approximation outside of the verified range of the current icing theory. Thus, calculations with the full droplet distribution spectrum are recommended.
\end{abstract}

Keywords: Ice accretion; Ice density; Ice thickness; Cylinder; Droplet distribution spectrum; MVD.

\section{INTRODUCTION}

The interest in modeling ice accretion on cylindrical objects primarily comes from preventing structural damage or collapse of objects such as overhead transmission lines or communication masts due to the accreted ice mass leading to dynamical instabilities. The theoretical modelling of icing is covered by ISO 12494, where the icing theory framework is valid for the droplet overall collision efficiency range of $0.07<E<0.63$ (Makkonen $e t$ al., 2018), though, the ISO 12494 model framework scope is rather limited when it comes to the long term modeling of the in-cloud icing events on the power lines and structures. Such long-term icing events can lead to significant ice loads over longer timeframes, where the ice can accrete in multiple "stages" under different operating conditions. These events can be more critical in remote areas, where frequent monitoring of structures and accreted ice is unlikely.

The primary attribute of continued ice accretion, which is the change of the object's characteristic length, in case of circular structures this length being the diameter, have been theoretically modeled by (Makkonen, 1984). However, the accreted ice mass and its density govern the change in the object's diameter. While the accreted ice mass and its modeling is the primary focus of the ISO 12494 theoretical framework, the accreted ice density

40 had received less attention in it. This may be critical if direct measurements of the accreted ice deposit on the structure cannot be performed and only indirect measurements such as visual estimation of deposit thickness can be performed.

Currently, there are several empirical accreted ice density formulations, such as (Macklin, 1962), (Pfaum and Pruppacher, 1979), (Bain and Gayet, 1983), (Makkonen and Stallabrass, 1984), (Jones 1990) etc. As noted in 45 (Jones, 1990) all empirical ice density formulations, which are based on the usage of the Macklin parameter, were obtained based on the cold room icing wind tunnel experimental results (Macklin, 1962), (Makkonen and Stallabrass, 1984), instrumented wind tunnel in natural conditions (Bain and Gayet, 1983), or in cloud chamber (Pfaum and Pruppacher, 1979). On the contrary, the empirical ice density in (Jones, 1990) was developed based on the multicylinder measurements in natural conditions on Mt. Washington.

50 These empirical ice density formulations are also incorporated in the modern CFD solvers, which have now become increasingly popular for the modeling of atmospheric icing on structures. Therefore, the focus of this study is to ascertain how these empirical icing density formulations, both in the analytical and numerical analyses are suitable for modeling of ice density and thickness, in order to investigate their suitability for modeling of long-term icing events, especially when the direct ice masses measurements are not available. 


\subsection{Analytical Model}

The cloud impingement parameters are calculated in accordance to (Finstad et al., 1988):

$$
\mathrm{X}(K, \phi)=\left[C_{X, 1} K^{C_{X, 2}} \exp \left(C_{X, 3} K^{C_{X, 4}}\right)+C_{X, 5}\right]-\left[C_{X, 6}(\phi-100)^{C_{X, 7}}\right] \times\left[C_{X, 8} K^{C_{X, 9}} \exp \left(C_{X, 10} K^{C_{X, 11}}\right)+C_{X, 12}\right]
$$

where $X$ is either the overall collision efficiency $E$, the stagnation line collision efficiency $\beta_{0}$, the maximum impingement angle $\alpha_{\max }$, or the non-dimensional impact velocity $V_{0}$. The values of constants $C_{X, n}$ can be found in (Finstad et al., 1988).

The spectrum-averaged cloud impingement parameters are calculated as:

$$
X(K, \phi)_{\text {spec }}=\sum w_{i} X\left(K_{i}, \varphi\right)
$$

where $K$ is the droplet inertia parameter, and $\varphi$ is the Langmuir parameter, defined as (Langmuir and Blodgett, 1946):

$$
\begin{gathered}
K_{i}=\frac{\rho_{\mathrm{a}} d_{i}^{2} v}{9 \mu_{\mathrm{a}} D} \\
\varphi=\frac{18 \rho_{\mathrm{a}}^{2} D v}{\rho_{\mathrm{d}} \mu_{\mathrm{a}}}=\frac{R e^{2}}{K}
\end{gathered}
$$

where $\rho_{\mathrm{a}}$ and $\rho_{\mathrm{d}}$ are air and droplet's densities, respectively, $\mu_{\mathrm{a}}$ is the density if air, $D$ is the cylinder diameter, $v$ is the operating wind speed and $R e$ is the droplet's Reynolds number. Moreover, $w$ is the volume fraction, $d_{i}$ is the droplet MVD with the subscript " $i$ " referring to the $i$ th bin of the droplet distribution spectrum and subscript "spec" referring to the spectrum-averaged values. In the analytical model the constraint $X_{i}\left(K_{i}, \varphi\right)=$ 0.01 for $K_{i} \leq 0.17$ is used as per (Finstad et al., 1988).

80 The ice deposit diameter $D_{i}$ of cylinder is calculated as (Makkonen, 1984):

$$
D_{i}=\left[\frac{4\left(M_{i}-M_{i-1}\right)}{\pi \rho_{\mathrm{i}}}+D_{i-1}^{2}\right]^{1 / 2}
$$

where $M$ is the mass accretion value per unit length, $\rho$ is the ice density and subscript $i$ indicates the time step. In all analytical calculations the time step used is $t=15$ seconds. This is to ensure that the cylinder rotates at least $360^{\circ}$ degrees along its longitudinal axis on each time step to ensure even ice deposit on the cylinder surface, in accordance with (Makkonen, 1984). The accreted ice density at any given time step is calculated as (Makkonen and Stallabrass, 1984):

$$
\rho_{\mathrm{i}}=378+425 \log _{10}(R)-82.3\left(\log _{10}(R)\right)^{2}
$$

where, $R$ is the Macklin ice density parameter, given as:

$$
R=-\frac{V_{0} d}{2 T_{s}}
$$

where $d$ is the MVD in microns, $V_{0}$ is the impact velocity of the droplet in $\mathrm{m} / \mathrm{s}$ and $T_{s}$ is the surface temperature of the ice deposit in Celsius. In the case of dry growth the surface temperature of the ice deposit can be obtained numerically as (Makkonen, 1984):

$$
\frac{2}{\pi} E v w\left(L_{f}+c_{w} t_{a}-c_{i} t_{s}\right)=h\left[\left(t_{s}-t_{s}\right)+\frac{k L_{s}}{c_{p} p_{a}}\left(e_{s}-e_{a}\right)-\frac{r v^{2}}{2 c_{p}}\right]+\sigma \alpha\left(t_{s}-t_{s}\right)
$$

where $L_{f}$ and $L_{s}$ are latent heats of fusion and sublimation respectively, $c_{w}, c_{i}$ and $c_{p}$ are specific heats of water, ice and air respectively, $p_{a}, e_{s}$ and $e_{a}$ are air pressure, saturation water vapor pressures at surface and air temperatures respectively, $h$ is the overall heat transfer coefficient, $k=0.62, r$ is the recovery factor with value of 0.79 being used for cylinder, $t_{s}$ and $t_{a}$ are surface and air temperatures in Celsius, $\sigma$ is the Stefan-Boltzmann constant and $\alpha=8.1 \times 10^{7} \mathrm{~K}^{3}$. More details on the terms of heat transfer and derivation of heat transfer equations are given in (Makkonen, 1984).

The "intermediate version" of icing density formulation of (Jones, 1990) is given as: 


$$
\begin{array}{lr}
\rho=0.210 R^{0.53} & R \leq 10 \\
\rho=R /(1.15 R+2.94) & 10<R<60 \\
\rho=0.84 & R \geq 60
\end{array}
$$

This parametric fit using the Macklin parameter was obtained using the best-fit curves for three out of six cylinders from the multicylinder device and the observational data from the Mt. Washington. The reason this particular fit is called "intermediate version" is, as noted in (Jones, 1990) it explains less than 50\% variation of the observed rime ice densities on the Mt. Washington. Therefore, (Jones, 1990) developed different empirical icing density formulation, using a range of mathematical and statistical arguments, as well as, employing the Buckingham $\pi$ theorem, statistical and multi-regression analysis. This "final version" of the Jones icing density formulation explains $80 \%$ of rime ice density variation on the Mt. Washington and is as (Jones, 1990):

$$
\rho=0.249-0.0840 \ln \pi_{C}-0.00624\left(\ln \pi_{\phi}\right)^{2}+0.135 \ln \pi_{K}+0.0185 \ln \pi_{K} \ln \pi_{\phi}-0.0339\left(\ln \pi_{K}\right)^{2}
$$

where $\pi_{K}$ is the droplet inertia coefficient, $\pi_{\varphi}$ is the Langmuir parameter and the term $\pi_{C}$ is the ratio of the convective heat flux and the heat flux due to droplet freezing and is defined as:

$$
\pi_{C}=\frac{k_{a}(-2 T) / D}{w v L_{f}}
$$

As noted in (Jones, 1990) when compared to the original empirical icing density formulation in (Macklin, 1962), the Jones ice density formulation should yield higher density values at lower values of the Macklin parameter $R$ and lower ice density values at high values of $R$. The (Makkonen and Stallabrass, 1984) and (Jones, 1990) empirical icing density formulations will be used in this study to test the performance of these ice density formulations obtained from rather different operating conditions. The choice of these two particular icing density formulations is governed by the fact that they are implemented in their original form in the numerical model, which is detailed in the following subsection.

\subsection{Numerical Model}

140 The multiphase Computational Fluid Dynamics (CFD) based numerical simulations are carried out using ANSYS FENSAP-ICE, which uses Eulerian water droplet impingement solver. The general Eulerian two-phase model for viscous flow consists of the Navier-Stokes equations augmented by the droplets continuity and momentum equations (FENSAP-ICE User Manual):

$$
\begin{gathered}
\frac{\partial \alpha}{\partial t}+\vec{\nabla} \cdot\left(\alpha \overrightarrow{V_{d}}\right)=0 \\
\frac{\partial\left(\alpha \overrightarrow{V_{d}}\right)}{\partial t}+\vec{\nabla}\left[\alpha \overrightarrow{V_{d}} \otimes \overrightarrow{V_{d}}\right]=\frac{C_{D} R e_{d}}{24 K} \alpha\left(\overrightarrow{V_{a}}-\overrightarrow{V_{d}}\right)+\alpha\left(1-\frac{\rho_{\mathrm{a}}}{\rho_{\mathrm{d}}}\right) \frac{1}{F r^{2}}
\end{gathered}
$$

where the variables $\alpha$ and $V_{d, a}$ are mean field values of, respectively, the water volume fraction and droplet velocity. The first term on the right-hand-side of the momentum equation represents the drag acting on droplets of mean diameter $d$. It is proportional to the relative droplet velocity, its drag coefficient $C_{D}$ and the droplets Reynolds number:

$$
\operatorname{Re}_{d}=\frac{\rho_{\mathrm{a}} d V_{a, \infty}\left\|\overrightarrow{V_{a}}-\overrightarrow{V_{d}}\right\|}{\mu_{\mathrm{a}}}
$$

and an inertia parameter:

$$
K=\frac{\rho_{\mathrm{d}} d^{2} V_{a, \infty}}{18 L_{\infty} \mu_{a}}
$$

160 where $L_{\infty}$ is the characteristic length of the object. In case of the cylinder, the characteristic length is cylinder radius as opposed to diameter in analytical model. However, the use of a constant 18 in denominator ensures that inertia parameters are equal in analytical and numerical models. The second term represents buoyancy and gravity forces and is proportional to the local Froude number:

$$
\operatorname{Fr}=\frac{\left\|V_{a, \infty}\right\|}{\sqrt{L_{\infty} g_{\infty}}}
$$


These governing equations describe the same physical droplets phenomenon as Lagrangian particle tracking approach. Only the mathematical form in which these equations are derived changes using Partial Differential Equations instead of Ordinary Differential Equations. The droplet drag coefficient is based on an empirical correlation for flow around spherical droplets, or:

$$
\begin{array}{lll}
C_{D}=\left(24 / R e_{d}\right)\left(1+0.15 \operatorname{Re}_{d}{ }^{0.687}\right) & \text { for } & \operatorname{Re}_{d} \leq 1300 \\
C_{D}=0.4 & \text { for } & \operatorname{Re}_{d}>1300
\end{array}
$$

The local and overall collision efficiencies are calculated following a completely different approach, when compared to Finstad et al. The local and overall collision efficiencies are calculated as follows:

$$
\beta=-\frac{\alpha \overrightarrow{V_{d}} \cdot \vec{n}}{w V_{\infty}}
$$

where $\alpha$ is the local volume fraction $\left(\mathrm{kg} / \mathrm{m}^{3}\right)$ and $\vec{n}$ is the surface normal vector. The overall collision efficiency is an integration of local collision efficiencies over surface area and is given as:

$$
\beta_{\text {tot }}=\frac{\int \beta \mathrm{d} A}{L_{\infty}^{2}}
$$

The turbulence model used in this study is Menster's SST $k-\omega$ model (FENSAP-ICE User Manual), (Wilcox, 1988). For surface roughness NASA sand-grain roughness model is used which is computed with an empirical NASA correlation for icing (FENSAP-ICE User Manual), (Shin and Bond, 1992).

Finally, the icing density formulations used in the numerical model are (Makkonen and Stallabrass, 1984) (referred in FENSAP-ICE as "Macklin") and both intermediate (referred in FENSAP-ICE as "Jones (glaze)") and the actual final rime ice density formulation (Jones, 1990), (referred in FENSAP-ICE as "Jones (rime)"), with their mathematical formulations being identical to formulations given in previous section. In order to avoid the potential confusion with the naming of different icing density parameterizations, the "M\&S" will be used to refer to Makkonen and Stallabrass fit and "Jones (glaze)" and "Jones (rime)" will be used to refer to the intermediate and final versions, respectively, of the Jones icing density formulations. This naming convention will be used from this point throughout the rest of manuscript.

\subsection{Experimental Setup}

The icing wind tunnel experiments were conducted at Cranfield University icing wind tunnel facility. This is a "closed-loop" tunnel with $761 \times 761 \mathrm{~mm}$ test section and is capable of operating wind speeds of Mach 0.1 to Mach 0.5, with wide range of possible droplet sizes and Liquid Water Content (LWC) due to flexible spray bars configuration. The operating parameters used for this study are summarized in Table 1.

Table 1. Operating conditions.

\begin{tabular}{|c|c|}
\hline Parameter & Value \\
\hline Cylinder diameter $(\mathrm{mm})$ & $20,50.05,80.25,99,149.5,249,298$ \\
\hline Air velocity $(\mathrm{m} / \mathrm{s})$ & 30 \\
\hline Air temp. $\left({ }^{\circ} \mathrm{C}\right)$ & -25 \\
\hline Altitude $(\mathrm{m} . \mathrm{a} . \mathrm{g} . \mathrm{l})$ & 0 \\
\hline MVD $(\mu \mathrm{m})$ & 16.36 \\
\hline Liquid Water Content $\left(\mathrm{g} / \mathrm{m}^{3}\right)$ & 0.6 \\
\hline Icing duration $(\mathrm{min})$ & 20 (for $20-80 \mathrm{~mm}), 30$ (for $99-298 \mathrm{~mm}$ diameter cylinders) \\
\hline Cylinder length $(\mathrm{mm})$ & $50.04,50,67.85,69.5,83.5,111.74,50,50$ \\
\hline
\end{tabular}

205 The choice of the operating air temperature is based on the need to maintain the "dry growth" regime during experimentation so that the sticking and accretion efficiencies, $\alpha_{2}=\alpha_{3}=1$, respectively. The choice of LWC and MVD is based on the need to obtain a measurable ice thickness, while simultaneously keeping the droplet inertia parameter $K$ low. The choice of wind speed corresponds to the minimum rated wind speed for the Cranfield University icing wind tunnel. During the experiments, the rotating multicylinder device, mounted in 210 the center of the test section, was used. The rotational velocity during the experiments was set to 4 RPM. Two cylinder configurations were tested - the configuration consisting of smaller cylinders $20-80.25 \mathrm{~mm}$ in diameter, and a configuration, consisting of larger cylinders, $99-298 \mathrm{~mm}$ in diameter. The reason for testing two different configurations is that the used multicylinder device can only allow mounting of four cylinders at a time.

215 The choice of only rotating cylinder is based on several considerations, primarily:

1. To keep the results strictly within ISO 12494 modeling framework. 
2. According to the experiments of (Makkonen and Stallabrass, 1984) on wires, the rate of rotation was in between 65 and $223 \mathrm{deg} / \mathrm{hr}$, with large jumps in rotation occurring. This implies that for longer time period of at least several hours of ice accretion the resultant ice shape will be circular.

220 3. Moreover, (Makkonen, 1984) referencing Howe and Dranevic states that the ratio of the minor to the major axis on actual power line conductors is 0.88 for glaze and 0.82 for rime, on the average.

4. Following personal discussions with Bjørn Eigil Nygård (Kjeller Vindteknikk AS, Norway) and, Egill Thorsteins (EFLA Iceland), it was noted that all significant ice accretions on test spans are circular in nature.

225 To minimize the effect of blockage, the multicylinder device was mounted as close as possible to the center of the tunnel's test-section. The duration of the tests was chosen to give a measurable thickness of the ice deposit. Since the large cylinder configuration has significantly lower values of droplet inertia parameter and by extension - the overall collision efficiency, the test duration was increased to $30 \mathrm{~min}$ for large configuration in order to offset this. During the experiments the cylinders were video recorded from multiple angles, in order to observe the ice growth in the details. Examples of final ice shapes from the experiments is given in Fig. 1.

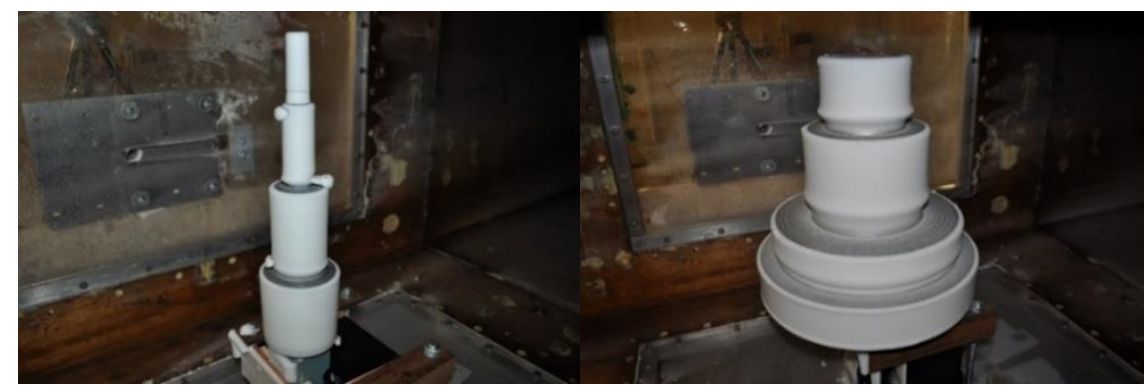

Fig. 1. Final ice shapes of the small (left) and large (right) cylinder configurations.

235 Figure 2 shows intermediate ice shapes for the larger cylinder configuration during the experimentation with 10 min increments and the final ice shapes for the individual cylinders.
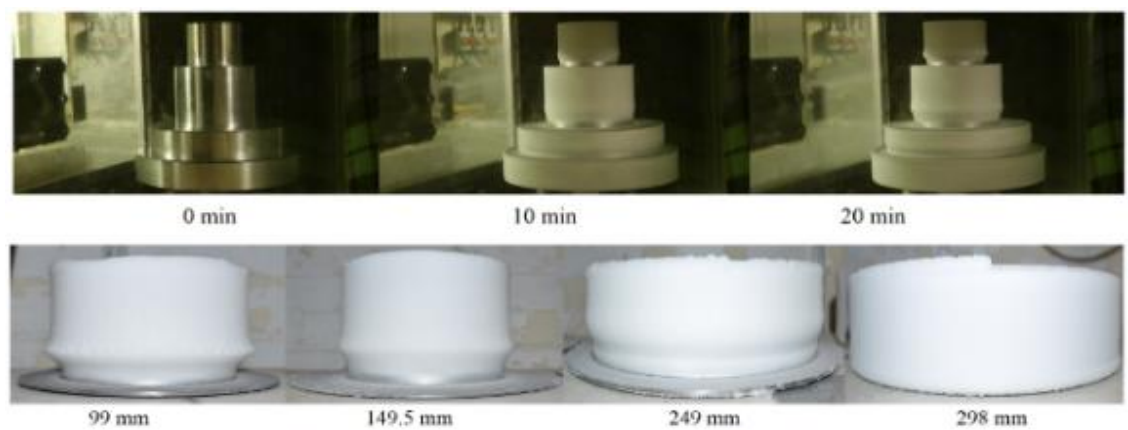

Fig. 2. Intermediate and final ice shapes for the large cylinder configuration. The respective diameters of each cylinders are indicated.

The droplet distribution spectrum from the icing wind tunnel is given in Fig. 3. The MVD of this distribution is $16.36 \mu \mathrm{m}$. The droplet distribution spectrum was measured using laser diffraction methods, while (Makkonen and Stallabrass, 1984) measured their experimental droplet distribution spectra using Forward Scattering Spectrometer Probe (FSSP) in addition to the common oiled and soothed slides methods, and (Jones, 1990) estimates LWC, MVD and droplet distribution spectra based on the numerical fitting of accreted ice on the multicylinder device at Mt. Washington observatory. In order to check the stability of the operating conditions during icing wind tunnel experiments the water and air pressure in the spray bar configuration was monitored constantly. The subsequent analysis of the water and air pressure fluctuations showed that these fluctuations are within $1 \%$ of the specified operating values. 


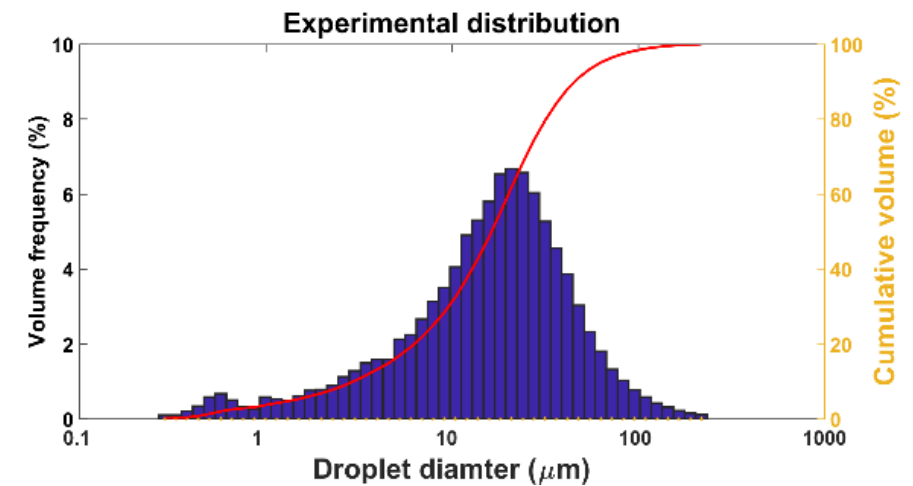

Fig. 3. Droplet distribution spectrum for the Cranfield University (CU) experimental cases.

\section{RESUltS AND DisCUSSION}

\subsection{Analytical Analysis}

Table 2 shows the values of the droplet inertia parameter, end iced cylinder diameter, denoted $D_{\text {end }}$ and the accreted ice density, respectively. The analytical results in Table 2 are given as spectrum-averaged mean values taken as average from all time steps and are calculated with the full droplet distribution spectrum from Fig. 3.

260 The experimentally measured values of the end iced cylinder diameters are given as a reference in the "Exp." column.

Table 2. Values of droplet inertia parameter, end cylinder diameter and accreted ice density in analytical calculations with full droplet distribution spectrum.

\begin{tabular}{|c|c|c|c|c|c|c|c|c|c|c|}
\hline \multirow{2}{*}{$\begin{array}{c}D \\
(\mathrm{~mm})\end{array}$} & \multicolumn{3}{|c|}{$K$} & \multicolumn{4}{|c|}{$D_{\text {end }}(\mathrm{mm})$} & \multicolumn{3}{|c|}{$\rho\left(\mathrm{kg} / \mathrm{m}^{3}\right)$} \\
\hline & $M \& S$ & $\begin{array}{c}\text { Jones } \\
\text { (glaze) }\end{array}$ & $\begin{array}{l}\text { Jones } \\
\text { (rime) }\end{array}$ & $\mathrm{M} \& \mathrm{~S}$ & $\begin{array}{c}\text { Jones } \\
\text { (glaze) }\end{array}$ & $\begin{array}{c}\text { Jones } \\
\text { (rime) }\end{array}$ & $\operatorname{Exp}$. & $M \& S$ & $\begin{array}{c}\text { Jones } \\
\text { (glaze) }\end{array}$ & $\begin{array}{c}\text { Jones } \\
\text { (rime) }\end{array}$ \\
\hline 20 & 9.623 & 9.188 & 10.069 & 29.70 & 32.39 & 27.34 & 32.30 & 636.9 & 495.8 & 856.0 \\
\hline 50.05 & 4.317 & 4.316 & 4.499 & 57.37 & 60.37 & 55.72 & 60.45 & 590.6 & 416.2 & 770.8 \\
\hline 80.25 & 2.871 & 2.821 & 2.890 & 86.25 & 89.28 & 85.10 & 87.57 & 554.5 & 366.2 & 690.3 \\
\hline 99 & 2.328 & 2.280 & 2.342 & 107.08 & 111.55 & 105.74 & 113.72 & 534.3 & 341.3 & 645.2 \\
\hline 149.5 & 1.586 & 1.566 & 1.590 & 156.02 & 160.27 & 160.30 & 155.36 & 488.5 & 293.7 & 545.9 \\
\hline 249 & 0.989 & 0.982 & 0.988 & 253.87 & 257.60 & 257.58 & 254.06 & 415.1 & 234.4 & 399.6 \\
\hline 298 & 0.840 & 0.836 & 0.839 & 302.38 & 305.83 & 302.91 & 307.06 & 384.3 & 214.2 & 342.9 \\
\hline
\end{tabular}

265 In general, the analytical values of end iced diameter calculated with the Jones (glaze) ice density formulation yields the closest agreement with the experimental values in most test cases. Comparatively, the M\&S and the Jones (rime) icing density formulations tends to underestimate the ice thicknesses for majority of cylinders with exceptions being 149.5 and $249 \mathrm{~mm}$ cylinders, for which the M\&S numerical fit gives the closest agreement with the experimental values. In addition, the Jones (glaze) icing density formulation has the lowest overall values of accreted ice densities, as evidenced from Table 2, with Jones (rime) Jones icing density formulation having highest values of accreted ice densities up to $249 \mathrm{~mm}$ cylinder, where the M\&S formulation shows the best agreement with experimental values.

When it comes to the spectrum-averaged results, the biggest difference will be in the values of the droplet inertia parameter $K$, when compared to the results with the MVD approximation. This increase in the value of $K$ will 275 lead to the increase of the droplet impact velocities, as follows from the structure of Eq. (1), which will, correspondingly, increase the values of the Macklin parameter $R$. As noted in (Jones, 1990), the numerical fit of (Makkonen and Stallabrass, 1987) produces higher values of ice density than the original formulation by (Macklin, 1962). On the other hand, the Jones (glaze) formulation predicts higher densities for low values of $R$ and lower densities for high values of $R$ than were obtained by (Macklin, 1962).

280 This property of the spectrum-averaging can also explain why the Jones (rime) formulation tends to predict highest densities for almost all cases, with exception of two largest cylinder of 249 and $298 \mathrm{~mm}$ diameters. Instead of relying on the Macklin parameter, this formulation relies directly on the values of $K$ and $\varphi$. While $\varphi$ is independent of droplet diameter, the values of $K$ will increase dramatically when one foregoes MVD approximation for calculations with full droplet distribution spectrum, especially, with the distribution as "wide" as experimental distribution in Fig. 3.

On the subject of the MVD approximation, Table 3 shows the analytical results of the droplet inertia parameter, end cylinder diameters and ice densities, respectively, in analytical calculations using MVD approximation as per ISO 12494 modeling framework. The primary interest in producing these values using the MVD 
approximation is to examine how the spectrum-averaged values compare to those, obtained by strict adherence with ISO 12494 modeling guidelines.

Table 3. Values of droplet inertia parameter, end cylinder diameter and accreted ice density in analytical calculations with the MVD approximation.

\begin{tabular}{|c|c|c|c|c|c|c|c|c|c|c|}
\hline \multirow{2}{*}{$\begin{array}{c}D \\
(\mathrm{~mm})\end{array}$} & \multicolumn{4}{|c|}{$K$} & \multicolumn{4}{c|}{$D_{\text {end }}(\mathrm{mm})$} & \multicolumn{3}{c|}{$\rho\left(\mathrm{kg} / \mathrm{m}^{3}\right)$} \\
\cline { 2 - 12 } & M\&S & $\begin{array}{c}\text { Jones } \\
\text { (glaze) }\end{array}$ & $\begin{array}{c}\text { Jones } \\
(\text { rime })\end{array}$ & M\&S & $\begin{array}{c}\text { Jones } \\
\text { (glaze) }\end{array}$ & $\begin{array}{c}\text { Jones } \\
(\text { rime })\end{array}$ & $\boldsymbol{E x p .}$ & M\&S & $\begin{array}{c}\text { Jones } \\
(\text { glaze })\end{array}$ & $\begin{array}{c}\text { Jones } \\
(\text { rime })\end{array}$ \\
\hline 20 & 2.239 & 2.174 & 2.257 & 29.72 & 32.10 & 30.07 & $\mathbf{3 2 . 3 0}$ & 649.0 & 521.1 & 641.1 \\
\hline 50.05 & 1.042 & 1.028 & 1.038 & 56.09 & 58.83 & 57.82 & $\mathbf{6 0 . 4 5}$ & 575.2 & 394.5 & 451.6 \\
\hline 80.25 & 0.672 & 0.669 & 0.670 & 84.34 & 86.91 & 86.85 & $\mathbf{8 7 . 5 7}$ & 502.3 & 308.3 & 313.9 \\
\hline 99 & 0.545 & 0.542 & 0.540 & 103.92 & 107.41 & 108.39 & $\mathbf{1 1 3 . 7 2}$ & 455.8 & 265.9 & 241.0 \\
\hline 149.5 & 0.366 & 0.367 & 0.362 & 152.6 & 155.07 & 159.36 & $\mathbf{1 5 5 . 3 6}$ & 329.2 & 184.9 & 100.0 \\
\hline 249 & 0.221 & 0.224 & 0.225 & 251.06 & 251.06 & 251.06 & $\mathbf{2 5 4 . 0 6}$ & 100.0 & 100.0 & 100.0 \\
\hline 298 & 0.185 & 0.187 & 0.188 & 300.06 & 300.06 & 300.06 & $\mathbf{3 0 7 . 0 6}$ & 100.0 & 100.0 & 100.0 \\
\hline
\end{tabular}

From Table 3 it can be seen that while the ice density and iced cylinder diameters are comparable to those in Table 2 for the smaller cylinder configuration of $20-80 \mathrm{~mm}$ cylinders as well as the $99 \mathrm{~mm}$ cylinder. For the $149.5 \mathrm{~mm}$ cylinder, the values of end cylinder diameter, while being lower than the spectrum-averaged values for all formulations, still agrees well with the experimental values.

However, the agreement in end cylinder diameter values becomes poor for the two largest cylinders, for which the calculated ice density is below the minimum constraint of $100 \mathrm{~kg} / \mathrm{m}^{3}$. This constraint is used in the analytical model as an assumed estimation on the lower bound of the accreted ice density. Moreover, when comparing the values of the droplet inertia parameter in Tables 2 and 3, the significantly lower values of $K$ in Table 3 will result in lower values of the cloud impingement parameters, in particular, when it comes to the droplet impact velocities and Macklin parameter values, thus significantly decreasing the accreted ice density values.

This, coupled with the MVD approximation yielding smaller values of end cylinder diameters for majority of cases in Table 6, will primarily result in an underestimation of the accreted ice masses calculated with MVD approximation, when compared to the spectrum-averaged results. This can potentially limit the applicability of using the MVD approximation in modeling of the long-term icing events, in particular when the droplet inertia parameter is low. Finally, for the MVD approximation both versions of the Jones formulation tend to be in good agreement for majority of cases, with obvious exception of two largest cylinders, where both of them are below constraint of $100 \mathrm{~kg} / \mathrm{m}^{3}$, unlike with the spectrum-averaged values, where Jones (rime) Jones shows consistently higher densities.

This does suggest that the procedure of spectrum-averaging might not be directly admissible for this formulation, due to significantly higher values of $K$ the spectrum-averaging method produces. Contrary, the M\&S and Jones (glaze) Jones formulations do not experience such sharp drop in values, as the effect on spectrum-averaging on the droplet impact velocities is not as pronounced as in the case with droplet inertia parameter, with the increase in droplet impact velocities being enough to offset the ice densities going below constraint in the spectrum-averaged values.

\subsection{Numerical Analysis}

320 Table 4 shows the results from the CFD simulations using the full droplet distribution spectrum from Fig. 3.

Table 4. Values of droplet inertia parameter, end cylinder diameter and accreted ice density in numerical calculations with full droplet distribution spectrum.

\begin{tabular}{|c|c|c|c|c|c|c|c|c|c|c|}
\hline \multirow{2}{*}{$\begin{array}{c}D \\
(\mathrm{~mm})\end{array}$} & \multicolumn{4}{|c|}{$K$} & \multicolumn{4}{c|}{$D_{\text {end }}(\mathrm{mm})$} & \multicolumn{3}{c|}{$\rho\left(\mathrm{kg} / \mathrm{m}^{3}\right)$} \\
\cline { 2 - 12 } & M\&S & $\begin{array}{c}\text { Jones } \\
(\text { glaze })\end{array}$ & $\begin{array}{c}\text { Jones } \\
(\text { rime })\end{array}$ & M\&S & $\begin{array}{c}\text { Jones } \\
\text { (glaze) }\end{array}$ & $\begin{array}{c}\text { Jones } \\
(\text { rime })\end{array}$ & Exp. & M\&S & $\begin{array}{c}\text { Jones } \\
(\text { glaze })\end{array}$ & $\begin{array}{c}\text { Jones } \\
(\text { rime })\end{array}$ \\
\hline 20 & 4.747 & 6.683 & 9.427 & 79.68 & 50.80 & 30.19 & $\mathbf{3 2 . 3 0}$ & 40.7 & 111.1 & 473.8 \\
\hline 50.05 & 4.308 & 4.040 & 4.349 & 59.78 & 67.06 & 58.74 & $\mathbf{6 0 . 4 5}$ & 376.4 & 202.3 & 425.1 \\
\hline 80.25 & 2.799 & 2.694 & 2.819 & 88.80 & 95.35 & 87.57 & $\mathbf{8 7 . 5 7}$ & 333.8 & 181.9 & 392.9 \\
\hline 99 & 2.320 & 2.216 & 2.276 & 104.92 & 114.50 & 108.85 & $\mathbf{1 1 3 . 7 2}$ & 425.9 & 233.0 & 376.7 \\
\hline 149.5 & 1.560 & 1.525 & 1.540 & 153.77 & 160.77 & 157.69 & $\mathbf{1 5 5 . 3 6}$ & 444.6 & 246.9 & 343.8 \\
\hline 249 & 0.945 & 0.936 & 0.940 & 251.75 & 256.37 & 254.55 & $\mathbf{2 5 4 . 0 6}$ & 444.7 & 246.9 & 295.0 \\
\hline 298 & 0.792 & 0.786 & 0.787 & 299.70 & 304.36 & 302.87 & $\mathbf{3 0 7 . 0 6}$ & 440.5 & 243.7 & 276.9 \\
\hline
\end{tabular}

In general, the CFD simulations show good agreement with the analytical modeling results for the iced cylinder diameters for $80-149.5 \mathrm{~mm}$ cylinders. For the $50 \mathrm{~mm}$ cylinder, the agreement depends on the formulation used, i.e., M\&S and Jones (rime) formulations show better agreement than the Jones (glaze) formulation. For the $20 \mathrm{~mm}$ cylinder only Jones (rime) formulation shows good agreement with the rest of formulations producing significantly higher end iced diameters. Moreover, observe that the ice density values in the CFD simulations are consistently lower than in analytical model, with exception of 249 and $298 \mathrm{~mm}$ cylinders. The primary reason for it is the difference in the flow treatment between the analytical and the numerical model, as 
the analytical model uses the potential flow approximation, as opposed to viscid turbulent flow in the CFD simulations.

In particular, the difference in the accreted ice density between two models simplifies to the difference in the stagnation line impact velocities, which are used in the calculation of the Macklin parameter as given in Eq. (7). Since for majority of cylinders, the analytical and the numerical results tend to have relatively comparable end iced cylinder diameters, this suggests that the CFD simulations produce consistently lower ice accretion masses as well, which may be detrimental, if the long-term extreme value ice modeling is needed. Table 5 shows the CFD simulations results using the MVD approximation. Again, the reason for this is to keep the results consistent with the ISO 12494 framework and to allow direct comparison with the results in Table 3 .

Table 5. Values of droplet inertia parameter, end cylinder diameter and accreted ice density in numerical calculations with the MVD approximation.

\begin{tabular}{|c|c|c|c|c|c|c|c|c|c|c|}
\hline \multirow{2}{*}{$\begin{array}{c}D \\
(\mathrm{~mm})\end{array}$} & \multicolumn{3}{|c|}{$K$} & \multicolumn{4}{c|}{$D_{\text {end }}(\mathrm{mm})$} & \multicolumn{3}{c|}{$\rho\left(\mathrm{kg} / \mathrm{m}^{3}\right)$} \\
\hline 20 & 2.133 & 1.859 & 2.226 & 32.44 & 40.17 & 30.25 & $\mathbf{3 2 . 3 0}$ & 374.1 & 201.1 & 473.8 \\
\hline (glaze) & $\begin{array}{c}\text { Jones } \\
\text { (rime) }\end{array}$ & M\&S & $\begin{array}{c}\text { Jones } \\
\text { (glaze) }\end{array}$ & $\begin{array}{c}\text { Jones } \\
(\text { rime })\end{array}$ & $\boldsymbol{E x p .}$ & M\&S & $\begin{array}{c}\text { Jones } \\
(\text { glaze })\end{array}$ & $\begin{array}{c}\text { Jones } \\
(\text { rime })\end{array}$ \\
\hline 50.05 & 1.054 & 1.014 & 1.047 & 56.11 & 60.28 & 56.74 & $\mathbf{6 0 . 4 5}$ & 471.9 & 270.1 & 425.1 \\
\hline 80.25 & 0.677 & 0.662 & 0.678 & 84.93 & 88.76 & 84.70 & $\mathbf{8 7 . 5 7}$ & 373.4 & 200.7 & 392.9 \\
\hline 99 & 0.555 & 0.548 & 0.552 & 102.58 & 105.06 & 103.60 & $\mathbf{1 1 3 . 7 2}$ & 486.4 & 283.9 & 376.7 \\
\hline 149.5 & 0.372 & 0.371 & 0.371 & 150.99 & 152.02 & 151.65 & $\mathbf{1 5 5 . 3 6}$ & 494.6 & 292.2 & 342.8 \\
\hline 249 & 0.225 & 0.224 & 0.224 & 249.33 & 249.56 & 249.53 & $\mathbf{2 5 4 . 0 6}$ & 481.4 & 278.9 & 295.0 \\
\hline 298 & 0.188 & 0.188 & 0.188 & 298.26 & 298.56 & 298.45 & $\mathbf{3 0 7 . 0 6}$ & 473.5 & 271.5 & 276.9 \\
\hline
\end{tabular}

The results from Table 5, when compared with the experimental values and the results from Table 3, do produce good agreement for the smaller cylinder configuration, in particular, for the 50 and $80 \mathrm{~mm}$ cylinders with Jones (glaze) formulation, and for $20 \mathrm{~mm}$ cylinder, using the $\mathrm{M} \& \mathrm{~S}$ and the Jones (rime) formulations. However, for the 149.5, 249 and $298 \mathrm{~mm}$ cylinders the MVD approximation barely shows any ice accretion, as end iced cylinder diameters are practically unchanged from un-iced diameters.

Furthermore, CFD results with the MVD approximation have somewhat higher values of the accreted ice density than the simulations using the full droplet distribution spectrum, with the exception of Jones (rime) formulation where full droplet distribution spectrum and the MVD approximation values for the ice density are comparable. This difference can be explained by either the difference in surface temperature, differences in the flow regime, primarily due to boundary layer differences, averaging procedures for the full droplet distribution spectrum in the CFD software, or combination of these factors.

Advantageously, the CFD simulations allow for detailed investigation of these details. From the CFD results, the boundary layer is much more pronounced in the simulations using the full droplet distribution spectrum. In addition, the droplet velocity gradients are much more "sharp" for the simulations with full droplet distribution spectrum, while the droplet velocities are higher in the case of simulations with monodisperse distribution. This may explain the higher ice density values in the results using the MVD approximation, and why the results for smaller cylinders in Tables 4 and 5 generally agree for cases with higher $K$ values; as this thicker boundary layer is actively "deflecting" the droplets away from the cylinder. In addition, this can probably explain the considerably higher thicknesses in the analytical results for the 249 and $298 \mathrm{~mm}$ cylinders, as the boundary layer is not present in the potential flow approximation, which is used in the analytical results. As an example, Fig. 4 shows the droplet velocity streamlines for a few selected cases in the CFD simulations.

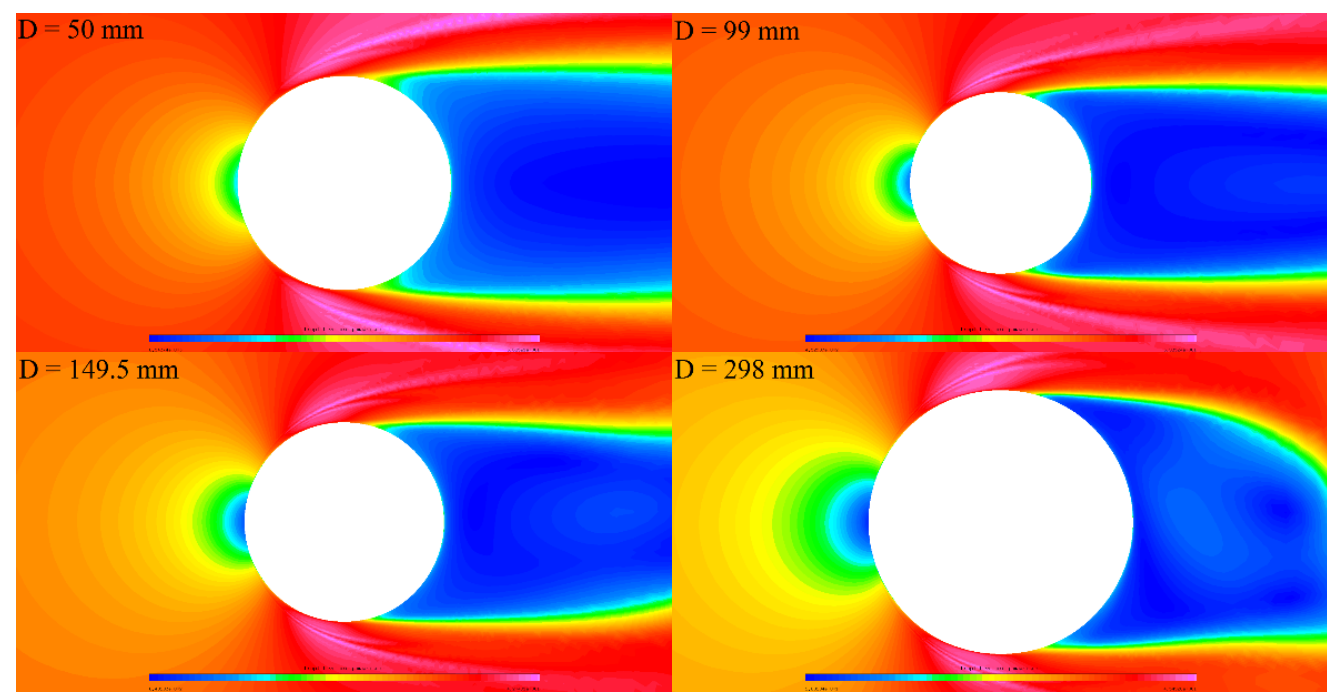

Fig. 4. Droplet velocity contours in the CFD simulations. 
In Fig. 4, the boundary layer is much more pronounced for the $298 \mathrm{~mm}$ and $149 \mathrm{~mm}$ cylinders, while for 50 $\mathrm{mm}$ cylinder it is barely visible. This thick boundary layer results in more pronounced flow separation for the larger cylinders. Again, this is possible explanation why the CFD simulations with the full droplet distribution spectrum tend to underestimate the accreted ice density values, when compared to the analytical and the MVD approximation results, as the impact velocities would be lower in this situation, as the thick boundary layer will "push out" the droplets from the stagnation region.

375 Based on the comparison of the results between the MVD approximation and full droplet distribution spectrum, it can be seen that the MVD approximation works well for higher values of droplet inertia parameter. This agrees with statements by (Makkonen et al., 2018) and (ISO, 2001) that the current icing parameterization is applicable for the range of the overall collision efficiency of $0.07<E<0.63$ and that for $E<0.1$ the icing parameterization using MVD approximation will underestimate the ice accretion, respectively.

380 Thus, in modeling of long-term icing events with expected low values of the droplet inertia parameter and the overall collision efficiency, the use of full droplet distribution spectrum is advantageous, as it can reliably reproduce accumulated thicknesses in most extreme cases, as evidenced from the results of this study. Still, for the more extreme cases, e.g. 249 and $298 \mathrm{~mm}$ cylinders, which have very low values of the droplet inertia parameter, even full droplet distribution spectrum may underestimate the icing intensity. In those cases, the recalculation of droplet trajectories using full drag terms is advised (Finstad et al., 1988).

\section{VALIDATION}

For the validation purposes the experimental cases from the FRonTLINES (Frost and Rime on The Overhead Transmission Line) have been selected. These test cases are characterized by the low values of the droplet inertia parameter, $K$, for most of them, except the test cases at $7 \mathrm{~m} / \mathrm{s}$ wind speeds for which, the $K$ value lies in "verified range". The detailed information regarding the operating conditions in these experiments as well as the experimental droplet distribution spectrum are given in (Makkonen et al., 2018). Unlike the previous experimental cases, discussed previously in this work, in the FRonTLINES cases the end iced masses are known, while the end cylinder diameters are unknown. Thus, this combination allows for validation of the analytical calculation procedure for the overall collision efficiency and total accreted ice mass. The results of analytical calculations for the FRonTLINES test cases are given in Tables 6 and 7 for the experimental droplet distribution spectrum and the MVD approximation, respectively.

Table 6. Analytical results for FRonTLINES experimental cases with the experimental droplet distribution spectrum. The number in brackets shows the wind speed in $\mathrm{m} / \mathrm{s}$.

\begin{tabular}{|c|c|c|c|c|c|c|c|c|}
\hline $\mathrm{D}$ & $\mathrm{D}_{\text {end }}(\mathrm{mm})$ & $\mathrm{K}$ & $\rho\left(\mathrm{kg} / \mathrm{m}^{3}\right)$ & $\mathrm{M}(\mathrm{g})$ & $\mathrm{M}_{\exp }(\mathrm{g})$ & $\mathrm{E}$ & $\mathrm{E}_{\exp }$ \\
\hline \multicolumn{7}{|c|}{$\mathrm{M} \& \mathrm{~S}$} \\
\hline $30(4)$ & 30.52 & 0.471 & 404.3 & 1.560 & 1.163 & 0.115 & 0.086 \\
\hline 50 & 50.39 & 0.306 & 276.8 & 1.321 & 0.722 & 0.058 & 0.032 \\
\hline 80 & 80.40 & 0.229 & 140.0 & 1.112 & 0.743 & 0.031 & 0.021 \\
\hline $100(4)$ & 100.41 & 0.209 & 100.0 & 1.020 & 0.770 & 0.023 & 0.017 \\
\hline 170 & 170.23 & 0.181 & 100.0 & 0.973 & 0.812 & 0.013 & 0.011 \\
\hline $30(7)$ & 31.07 & 0.796 & 574.0 & 4.600 & 4.211 & 0.194 & 0.177 \\
\hline $100(7)$ & 100.43 & 0.280 & 336.2 & 3.549 & 4.754 & 0.045 & 0.060 \\
\hline \multicolumn{7}{|c|}{ Jones (glaze) } \\
\hline $30(4)$ & 30.92 & 0.469 & 226.2 & 1.556 & 1.163 & 0.115 & 0.086 \\
\hline 50 & 50.67 & 0.305 & 158.9 & 1.320 & 0.722 & 0.058 & 0.032 \\
\hline 80 & 80.50 & 0.229 & 112.7 & 1.112 & 0.743 & 0.031 & 0.021 \\
\hline $100(4)$ & 100.41 & 0.209 & 100.0 & 1.020 & 0.770 & 0.023 & 0.017 \\
\hline 170 & 170.23 & 0.181 & 100.0 & 0.973 & 0.812 & 0.013 & 0.011 \\
\hline $30(7)$ & 31.56 & 0.790 & 391.5 & 4.600 & 4.211 & 0.194 & 0.177 \\
\hline $100(7)$ & 100.77 & 0.280 & 186.5 & 3.546 & 4.754 & 0.045 & 0.060 \\
\hline \multicolumn{7}{|c|}{ Jones (rime) } \\
\hline $30(4)$ & 30.62 & 0.471 & 338.8 & 1.559 & 1.163 & 0.115 & 0.086 \\
\hline 50 & 50.50 & 0.305 & 213.6 & 1.321 & 0.722 & 0.058 & 0.032 \\
\hline 80 & 80.49 & 0.229 & 116.0 & 1.112 & 0.743 & 0.031 & 0.021 \\
\hline $100(4)$ & 100.41 & 0.209 & 100.0 & 1.020 & 0.770 & 0.023 & 0.017 \\
\hline 170 & 170.23 & 0.181 & 100.0 & 0.973 & 0.812 & 0.013 & 0.011 \\
\hline $30(7)$ & 31.27 & 0.793 & 483.3 & 4.600 & 4.211 & 0.194 & 0.177 \\
\hline $100(7)$ & 100.84 & 0.280 & 170.8 & 3.546 & 4.754 & 0.045 & 0.060 \\
\hline
\end{tabular}

Table 7. Analytical results for FRonTLINES experimental cases with the MVD approximation. The number in brackets shows the wind speed in $\mathrm{m} / \mathrm{s}$.

\begin{tabular}{|l|l|l|l|l|l|l|c|}
\hline $\mathrm{D}$ & $\mathrm{D}_{\text {end }}(\mathrm{mm})$ & $\mathrm{K}$ & $\rho\left(\mathrm{kg} / \mathrm{m}^{3}\right)$ & $\mathrm{M}(\mathrm{g})$ & $\mathrm{M}_{\exp }(\mathrm{g})$ & $\mathrm{E}$ & $\mathrm{E}_{\exp }$ \\
\hline \multicolumn{10}{|c|}{$\mathrm{M} \& \mathrm{~S}$} \\
\hline
\end{tabular}




\begin{tabular}{|c|c|c|c|c|c|c|c|}
\hline $30(4)$ & 30.34 & 0.302 & 305.1 & 0.767 & 1.163 & 0.057 & 0.086 \\
\hline 50 & 50.18 & 0.182 & 100.0 & 0.226 & 0.722 & 0.010 & 0.032 \\
\hline 80 & 80.18 & 0.170 & 100.0 & 0.362 & 0.743 & 0.010 & 0.021 \\
\hline $100(4)$ & 100.18 & 0.170 & 100.0 & 0.453 & 0.770 & 0.010 & 0.017 \\
\hline 170 & 170.18 & 0.170 & 100.0 & 0.769 & 0.812 & 0.010 & 0.011 \\
\hline $30(7)$ & 30.86 & 0.524 & 550.1 & 3.555 & 4.211 & 0.150 & 0.177 \\
\hline $100(7)$ & 100.32 & 0.170 & 100.0 & 0.793 & 4.754 & 0.010 & 0.060 \\
\hline \multicolumn{7}{|c|}{ Jones (glaze) } \\
\hline $30(4)$ & 30.60 & 0.300 & 171.0 & 0.762 & 1.163 & 0.056 & 0.086 \\
\hline 50 & 50.18 & 0.182 & 100.0 & 0.226 & 0.722 & 0.010 & 0.032 \\
\hline 80 & 80.18 & 0.170 & 100.0 & 0.362 & 0.743 & 0.010 & 0.021 \\
\hline $100(4)$ & 100.18 & 0.170 & 100.0 & 0.453 & 0.770 & 0.010 & 0.017 \\
\hline 170 & 170.18 & 0.170 & 100.0 & 0.769 & 0.812 & 0.010 & 0.011 \\
\hline $30(7)$ & 31.31 & 0.520 & 359.6 & 3.542 & 4.211 & 0.149 & 0.177 \\
\hline $100(7)$ & 100.32 & 0.170 & 100.0 & 0.793 & 4.754 & 0.010 & 0.060 \\
\hline \multicolumn{7}{|c|}{ Jones (rime) } \\
\hline $30(4)$ & 30.49 & 0.301 & 209.9 & 0.764 & 1.163 & 0.056 & 0.086 \\
\hline 50 & 50.18 & 0.182 & 100.0 & 0.226 & 0.722 & 0.010 & 0.032 \\
\hline 80 & 80.18 & 0.170 & 100.0 & 0.362 & 0.743 & 0.010 & 0.021 \\
\hline $100(4)$ & 100.18 & 0.170 & 100.0 & 0.453 & 0.770 & 0.010 & 0.017 \\
\hline 170 & 170.18 & 0.170 & 100.0 & 0.769 & 0.812 & 0.010 & 0.011 \\
\hline $30(7)$ & 31.27 & 0.520 & 372.8 & 3.544 & 4.211 & 0.149 & 0.177 \\
\hline $100(7)$ & 100.32 & 0.170 & 100.0 & 0.793 & 4.754 & 0.010 & 0.060 \\
\hline
\end{tabular}

In Tables 6 and 7, the end cylinder diameter in all cases changes insignificantly with maximum diameter increase being barely over $1 \mathrm{~mm}$. This primarily can be explained by the low values of $K$ and the choice of operating conditions, namely, the LWC being equal to $0.4 \mathrm{~g} / \mathrm{m}^{3}$ with the test duration of $30 \mathrm{~min}$. for all cases. Moreover, the results in Table 7 show that the value of $K$ is low enough that for majority of cases the constraint of $E=0.01$ if $K \leq 0.17$ (Finstad et al., 1988) is enforced. Thus, the analytical results with the MVD approximation tend to underestimate the ice masses and the overall collision efficiencies in most of these cases. On the other hand, the results with experimental droplet distribution spectrum show slightly elevated values of 410 these parameters in the analytical calculations. This may be explained by the nature of spectrum-averaging procedure, as while the smallest bins in the distribution will be bounded by the constraint of $E=0.01$ if $K \leq$ 0.17 , for larger bins, for which $K>0.17$, the collision efficiency value will be calculated "as normal". As a result, the overall collision efficiency values may be slightly overestimated, when compared to the experimental results, as evidenced in Table 6 .

415 When it comes to the values of the accreted ice densities in Tables 6 and 7, for the majority of cases the calculated accreted ice densities are below the constraint of $100 \mathrm{~kg} / \mathrm{m}^{3}$, in particular, for the results with the MVD approximation, where all cases, with the exception of $30 \mathrm{~mm}$ cylinder are below this constraint. The situation is a bit different for the spectrum-averaged results, where only two largest cylinders are below the constraint. For the cases where the calculated ice density is not below $100 \mathrm{~kg} / \mathrm{m}^{3}$, a large spread of values can 420 be observed in Tables 6 and 7, with majority of those lying in the range of $250-400 \mathrm{~kg} / \mathrm{m}^{3}$. This coupled with very low calculated end cylinder diameters suggests that in reality the uniform layer of ice will not form and instead large, individual beads of rime ice will be present, as its expected that the individual bead height will be bigger than 0.5-1 mm, which is typical difference in the end and start diameter values in Tables 6 and 7 .

Thus, for additional validation, different experimental test cases were selected, with higher values of the droplet inertia parameter, namely, two cases from the experiments of (Makkonen and Stallabrass, 1984) - test cases 6 and 16. This particular choice was governed by several reasons, in particular the closeness of diameter values to the ISO 12494 "reference collector" (case 6) and the current "limit value" of verified cylinder diameter validity range (case 16). Moreover, the LWC and MVD values for these two cases are the highest when compared to other experimental cases with same cylinder diameters, thus giving the highest possible accreted 430 ice mass and thickness, compared to other experimental cases. The detailed operating conditions for these test cases is available in (Makkonen and Stallabrass, 1987) Table 1.

As noted in Table 1 in (Makkonen and Stallabrass, 1987) for the analytical calculations one of the three experimental droplet distribution spectra has been used, denoted as "Droplet size distribution category", however, due to significant passage of time the exact information on these droplet distributions is no longer available (Makkonen, personal communication). Thus, for the purpose of the modeling in this paper, these two test cases have been analyzed using the monodisperse distribution, as per ISO 12494 guidelines and the Langmuir D distribution, as it is a common distribution in in-flight icing studies. The results from analytical modeling are given in Table 8.

Table 8. Analytical results for two test cases of (Makkonen and Stallbrass, 1987). 


\begin{tabular}{|c|c|c|c|c|c|c|c|c|c|c|c|}
\hline Test & $\begin{array}{c}\text { Distrib } \\
\text { ution }\end{array}$ & $\bar{K}$ & $\begin{array}{c}\text { Dend } \\
(\mathrm{mm})\end{array}$ & $\begin{array}{l}D_{\text {end }} \\
\text { Exp } \\
(\mathrm{mm})\end{array}$ & $\begin{array}{c}\rho \\
\left(\mathrm{kg} / \mathrm{m}^{3}\right)\end{array}$ & $\begin{array}{c}\rho_{\exp } \\
\left(\mathrm{kg} / \mathrm{m}^{3}\right)\end{array}$ & $M(g)$ & $\begin{array}{c}M_{\exp } \\
(\mathrm{g})\end{array}$ & $\mathrm{E}$ & $E_{\text {theory }}$ & $E_{\exp }$ \\
\hline \multicolumn{12}{|c|}{$M \& S$} \\
\hline 6 & MVD & 1.115 & 36.15 & 36.50 & 762.8 & 746.1 & 17.533 & 18.70 & 0.299 & 0.30 & 0.32 \\
\hline 6 & LangD & 1.515 & 36.23 & 36.50 & 760.0 & 746.1 & 17.806 & 18.70 & 0.303 & 0.30 & 0.32 \\
\hline 16 & MVD & 0.491 & 78.38 & 79.50 & 660.4 & 710.3 & 18.296 & 29.6 & 0.110 & 0.14 & 0.18 \\
\hline 16 & LangD & 0.673 & 78.96 & 79.50 & 681.3 & 710.3 & 23.732 & 29.6 & 0.142 & 0.14 & 0.18 \\
\hline \multicolumn{12}{|c|}{ Jones (glaze) } \\
\hline 6 & MVD & 1.113 & 36.27 & 36.50 & 741.5 & 746.1 & 17.536 & 18.70 & 0.298 & 0.30 & 0.32 \\
\hline 6 & LangD & 1.513 & 36.35 & 36.50 & 738.5 & 746.1 & 17.814 & 18.70 & 0.302 & 0.30 & 0.32 \\
\hline 16 & MVD & 0.489 & 78.86 & 79.50 & 545.6 & 710.3 & 18.258 & 29.6 & 0.109 & 0.14 & 0.18 \\
\hline 16 & LangD & 0.672 & 79.37 & 79.50 & 595.9 & 710.3 & 23.722 & 29.6 & 0.141 & 0.14 & 0.18 \\
\hline \multicolumn{12}{|c|}{ Jones (rime) } \\
\hline 6 & MVD & 1.095 & 37.47 & 36.50 & 581.8 & 746.1 & 17.563 & 18.70 & 0.294 & 0.30 & 0.32 \\
\hline 6 & LangD & 1.500 & 36.94 & 36.50 & 654.7 & 746.1 & 17.851 & 18.70 & 0.301 & 0.30 & 0.32 \\
\hline 16 & MVD & 0.484 & 80.49 & 79.50 & 339.8 & 710.3 & 18.130 & 29.6 & 0.107 & 0.14 & 0.18 \\
\hline 16 & LangD & 0.667 & 80.53 & 79.50 & 437.8 & 710.3 & 23.694 & 29.6 & 0.140 & 0.14 & 0.18 \\
\hline
\end{tabular}

In Table 8 the variable " $E_{\text {theory }}$ " shows the values of the overall collision efficiency as calculated by (Makkonen and Stallabrass, 1987) for comparison purposes to the values of the overall collision efficiency $E$ as calculated in this work. Moreover, the variable " $\rho_{\text {exp }}$ " shows the experimental value of the accreted ice density, calculated based on the reported ice masses and ultimate cylinder diameters in (Makkonen and Stallabrass, 1987).

445 From Table 8 it can be seen that in analytical calculations, expectedly, the M\&S formulation shows the best agreement with experimental results, as this numerical fit was developed based on these experimental results. The Jones (glaze) formulation also shows good agreement for the $31.83 \mathrm{~mm}$ cylinder, however, it underestimates the value of accreted ice density for the $76.09 \mathrm{~mm}$ cylinder. In terms of accreted ice thicknesses in the analytical results, both Macklin and Jones (glaze) yield good agreement with the experimental values

450 while Jones (rime) parameterization tends to slightly overestimate the ice thicknesses.

By summarizing the analytical, numerical and experimental results following conclusions can be made:

- The M\&S formulation yields good agreement, in both the analytical and the numerical results for smaller cylinder configuration, $20-80 \mathrm{~mm}$ in diameter in the Cranfield University experimental cases and the 31.83 and $76.09 \mathrm{~mm}$ cylinders from the (Makkonen and Stallbrass, 1984) experimental cases.

455 - Both versions of the Jones formulation yield better agreement than the M\&S formulation for majority of cylinder diameters in the Cranfield University experimental cases.

- The results using the full droplet distribution spectrum yield good agreement with the experimental results, particularly for larger cylinders.

- The results using the MVD approximation only yield acceptable agreement for the smaller cylinder configuration and $31.83 \mathrm{~mm}$ cylinder from the (Makkonen and Stallbrass, 1984) experimental cases.

- Between the two Jones formulations, the intermediate (glaze) formulation shows better agreement with experimental values in analytical results with full droplet distribution spectrum and in numerical with the MVD approximation, except $20 \mathrm{~mm}$ cylinder, while final (rime) Jones formulation shows opposite results.

- The Jones (glaze) formulation in the Cranfield University cases performed admirably, considering the surface temperature in those conditions is expected to be below $-20^{\circ} \mathrm{C}$. This value is a rough "cutoff" as neither (Macklin, 1962) in his experiments nor (Jones, 1990), who employed similar analysis technique to obtain her intermediate version of the icing density parameterization, haven't tested and/or discarded cases with lower temperature during developing of their respective formulations.

- For the (Makkonen and Stallabrass, 1984) experimental cases, the M\&S and the Jones (glaze) parametrizations showed good agreement; however, Jones (rime) formulation was underestimating the ice density. The possible reasons for the underestimation of the experimental ice density by Jones parameterization in the (Makkonen and Stallabrass, 1984) experiments is given in (Jones, 1990).

\section{CONCLUSION}

In this paper the investigation into several empirical accreted ice density formulations have been conducted, with the main goal of assessing how well said empirical formulations can capture the accreted ice thicknesses. The practical purpose of it is to use the accreted ice thickness as a sort of icing severity estimate in modeling of the long-term icing events, if the accreted ice mass is an unknown value. The icing modeling in this study was done by using both the analytical modeling and the CFD simulations, in order to compare two most likely approaches of the modeling of the long term icing events. The obtained icing thicknesses were than compared 
The obtained results show that both the analytical and the numerical models can adequately estimate end iced cylinder diameters for majority of the tested cylinder diameters in this study. In particular, while the M\&S formulation tends to have good agreement with the smaller cylinder configuration, it tends to underestimate the icing thicknesses for the larger cylinder configuration. On the other hand, the Jones formulations show consistently better results for almost all tested cases, and especially, for the larger cylinder configuration. However, all formulations tend to underestimate the icing thicknesses for the largest cylinders, 249 and 298 $\mathrm{mm}$ in diameter.

These results were obtained using the full droplet distribution spectrum from the Cranfield University icing wind tunnel. In order to keep the results consistent with the framework of ISO 12494 icing theory, the matching set of values, using the monodisperse droplet distribution with the equal MVD was obtained. The results with the MVD approximation show good agreement mainly for smaller cylinder configuration, $20-80 \mathrm{~mm}$ in diameter, and the agreement for the larger cylinder diameter is non-satisfactory, primarily due to low values of droplet inertia parameter $K$ for these cases, which puts the results using the MVD outside of the verified range of the current icing theory. Thus, calculations with the full droplet distribution spectrum are recommended.

495 Summarizing the findings of the validation section, both tested formulations based on Macklin parameter, i.e., the numerical fit by Makkonen and Stallabrass and the intermediate version of Jones formulation have showed better agreement than the final version of Jones formulation, however, as noted in the original work (Jones, 1990) there are several reasons for this discrepancy.

\section{ACKNOWLEDGEMENTS}

500 The work reported in this paper is funded by the Research Council of Norway, IceBOX - project no. 282403 and WindCoE (Nordic Wind Energy Centre) project within the Interreg IVA Botnia-Atlantica, as part of European Territorial Cooperation (ETC). Authors would like to acknowledge Dr. David Hammond, Dr. Hugo Pervier and Mr. Peter West from Cranfield University, UK for assisting during icing tunnel experimentation.

\section{REFERENCES}

1. Bain, M. and Gayet, J. F., (1983). Contribution to the modeling of the ice accretion process. Pp. 1320 in Proceedings of the First International Workshop on Atmospheric Icing of Structures, U. S. Army CRREL Special Report 83-17.

2. Finstad, K.J., Lozowski, E.P., Gates, E.M., (1988). A computational investigation of water droplet trajectories. Journal of Atmospheric and Oceanic Technology, vol. 5, pp. 160-170.

3. FENSAP-ICE User Manual

4. ISO 12494:2001(E), (2001). Atmospheric icing of structures. Standard. International Organization for Standardization. Geneva, $\mathrm{CH}$.

5. Jones, K.F. (1990). The density of natural ice accretions related to nondimensional icing parameters, Quarterly Journal of Royal Meteorological Society, vol. 116, pp. 477-496.

6. Langmuir, I., Blodgett, K., (1946). A Mathematical Investigation of Water Droplet Trajectories. Army Air Forces technical report 5418. Army Air Forces Headquarters, Air Technical Service Command.

7. Macklin, W.C., (1962). The density structure of ice formed by accretion. Quarterly Journal of Royal Meteorological Society, vol. 88 pp. 30-50.

8. Makkonen, L., (1984). Modeling of Ice Accretion on Wires. Journal of Applied Meteorology, vol. 23, pp. 929-939.

9. Makkonen, L., Stallabrass J.R., (1984). Ice accretion on cylinders and wires. National Research Council of Canada. Division of Mechanical Engineering Technical Report TR-LT-05.

10. Makkonen, L., Stallabrass, J.R., (1987). Experiments on the cloud droplet collision efficiency of cylinders. Journal of Applied Meteorology, vol. 26, pp. 1406-1411.

11. Makkonen, L., Zhang, J., Karlsson, T., Tiihonen, M., (2018). Modelling the growth of large rime ice accretions, Cold Regions Science and technology, vol. 151, pp. 133-137.

12. Pfaum, J.C. and Pruppacher, H.R., (1979). A wind tunnel investigation of the growth of graupel initiated from frozen drops. Journal of Atmospheric Sciences, vol. 36, pp. 680-689. 
13. Shin, J. and Bond, T, (1992). Experimental and Computational Ice Shapes and Resulting Drag Increase for a NACA 0012 Airfoil, NASA Technical Manual 105743.

14. Wilcox, D.C., (1988). "Re-assessment of the scale-determining equation for advanced turbulence models", AIAA Journal, vol. 26, no. 11, pp. 1299-1310. 